\title{
Deslocamentos, desenlaces e tessituras no cuidado em alimentação e nutrição: análise de uma publicação oficial brasileira
}

\author{
Developments, implications and ramifications in food and \\ nutrition care: analysis of an official Brazilian publication
}

Lilian Miranda Magalhães (https://orcid.org/0000-0003-4964-052X) ${ }^{1}$

Ligia Amparo-Santos (https://orcid.org/0000-0002-6925-6421) ${ }^{1}$

Deborah Leão-Santos (https://orcid.org/0000-0002-8145-8747) ${ }^{2}$

Indira Ramos Gomes (https://orcid.org/0000-0002-6995-7877) ${ }^{3}$

${ }^{1}$ Departamento de Ciências da Nutrição, Universidade Federal da Bahia. R. Basilio da Gama s/n, Campus Canela. 40.110-907 Salvador BA Brasil. lilianmirandam@gmail.com ${ }^{2}$ Escola de Nutrição, Universidade Federal da Bahia. Salvador BA Brasil. ${ }^{3}$ Núcleo de Estudos e Pesquisas em Alimentação e Cultura, Universidade Federal da Bahia. Salvador BA Brasil.

\begin{abstract}
The scope of this paper is to analyze the discursive strategies of a Ministry of Health publication, by virtue of the fact that another notion of food and nutrition care (FNC) emerges from them. Through discourse analysis, the results are interpreted mainly in the light of Edgar Morin and Anemarie Mol's studies. The analysis identified elements of the complex thinking constituting a broadened perspective about the food and FNC practices in the context of matrix support. As the main discursive strategy, narratives contextualize care in sinuous and inconclusive scenarios, emphasizing the immanence of unpredictability and uncertainty. Metaphorical resources reveal displacements that remove the centrality of Biomedicine and weave in the subject the practical wisdom of dealing with the coexistence between the generality of body and food metrification and the uniqueness of everyday life and eating. The stories contribute to the understanding of FNC as shared management, which aims to restore viable and ever provisional order. In conclusion, by exposing and legitimizing the plurality of ways of acting, the document that emerges from and relates back to it can have repercussions on health education and raise the theoretical repertoire surrounding FNC practices.
\end{abstract}

Key words Primary health care, Matrix support, Food and nutrition, Healthcare
Resumo Este ensaio objetiva analisar as estratégias discursivas de uma publicação do Ministério da Saúde, considerando que delas emerge outra noção de cuidado em alimentação e nutrição (CAN). Por meio da análise de discurso, os resultados são interpretados principalmente à luz dos estudos de Edgar Morin e Annemarie Mol. A análise identificou elementos do pensamento complexo constitutivos de uma perspectiva ampliada acerca da alimentação e das práticas de CAN no contexto do apoio matricial. Como principal estratégia discursiva, narrativas contextualizam o cuidado em enredos sinuosos e inconclusos, enfatizando a imanência da imprevisibilidade e da incerteza. Recursos metafóricos revelam deslocamentos da centralidade da biomedicina e tecem no sujeito a sabedoria prática de lidar com a coexistência entre a generalidade da metrificação do corpo e da comida e a singularidade das vidas e do comer cotidiano. As histórias contribuem para a compreensão do CAN como manejo compartilhado, que visa a restituição da ordem - viável e sempre provisória. Como conclusão, ao expor e legitimar a pluralidade de modos de atuar, o documento que emerge da experiência e a ela se volta pode repercutir na formação em saúde e suscitar a ampliação do repertório teórico acerca das práticas de CAN.

Palavras-chave Atenção primária à saúde, Apoio matricial, Alimentação e nutrição, Cuidado em saúde 


\section{Introdução}

Há três décadas, houve no Brasil o reconhecimento do papel da alimentação adequada como condicionante e determinante da situação de saúde da população e a atenção primária à saúde (APS) passou a ser vista como um espaço estratégico para a promoção da alimentação saudável. Tais movimentos foram concebidos no curso de um processo histórico de democratização e abertura à participação social - com destaque para o Movimento da Reforma Sanitária, a criação do Sistema Único de Saúde, a institucionalização da Política Nacional de Alimentação e Nutrição (PNAN), entre outros ${ }^{1-4}$. A reorganização do modelo de atenção à saúde propiciou o aperfeiçoamento das práticas assistenciais, e a criação da Estratégia de Saúde da Família teve um importante papel para a consolidação da APS.

A atuação referenciada do apoio matricial em áreas estratégicas configurou-se como uma medida relevante para fomentar e conduzir ações de alimentação e nutrição nas unidades de saúde junto às equipes de referência ${ }^{1,2,5}$. Diversos documentos oficiais foram elaborados para orientar ações de alimentação e nutrição e a atuação dos profissionais inseridos nesse âmbito da atenção $0^{6-12}$. Contudo, assim como observado em artigos científicos nacionais e internacionais, nessas publicações técnicas a dimensão do cuidado em saúde relacionada a alimentação e nutrição é referida sob vários termos desprovidos de discussões conceituais.

Leituras exploratórias permitem constatar que o cenário de produções normativas apresenta uma compreensão limitada acerca dessa dimensão que integra o cuidado em saúde. As menções, geralmente restritas a caracterizações ou exemplificações, parecem pouco consistentes e ainda distantes do cotidiano das práticas de saúde, bem como do debate enquanto objeto do conhecimento científico.

Por outro lado, é necessário considerar que, ao longo do tempo, ocorreram mudanças significativas que resultaram na não-linearidade e na diversidade do processo de elaboração de referenciais técnicos. Ao lado de abordagens predominantemente comportamentais, focadas em condições consideradas patológicas ${ }^{13} \mathrm{e}$ prescritivas da atuação profissional ${ }^{14}$, foi identificada uma publicação que admitia e defendia a criação de outros modos de cuidado, relacionados a alimentação e nutrição ${ }^{12}$, apontando para uma possível noção emergente de cuidado, em contraposição à compreensão hegemônica fundada na heteronomia e na disciplinarização.
Assim, por seu caráter atípico, sua pertinência e sua especificidade em relação ao tema de interesse, o material de apoio técnico intitulado Contribuições dos Núcleos de Apoio à Saúde da Família para a Atenção Nutricional ${ }^{12}$ foi examinado com a intenção de analisar as estratégias discursivas adotadas nessa produção textual. Assim como discutir a noção de cuidado em alimentação e nutrição que delas parece emergir, considerando sua potencial influência sobre condutas terapêuticas e demais práticas de saúde em outros espaços de atenção e formação em saúde.

\section{Metodologia}

Tomando a análise de discurso ${ }^{14}$ como opção metodológica, ao longo do estudo foram examinados o contexto de produção, a autoria, a natureza, a produção de sentidos e a lógica interna do texto. Leituras repetidas e minuciosas propiciaram o refinamento analítico dos dados, que foram sistematizados e categorizados ${ }^{15}$. O processo de interpretação e discussão dos resultados foi desenvolvido por meio da interlocução com diversos autores, notadamente Edgar Morin ${ }^{16} \mathrm{e}$ Annemarie $\mathrm{Mol}^{17}$, cujos pensamentos nos auxiliaram a pensar a complexidade e o cuidado como construções conceituais e práticas.

O presente artigo está organizado em três momentos. Inicialmente, apresenta o documento-referência, considerando seu contexto de produção e as estratégias discursivas, que indicam a inclusão de elementos do pensamento complexo. Em seguida, analisa as estratégias discursivas adotadas nessa produção textual, em particular no capítulo que se refere aos casos fictícios, focando a cinesia e a experiência como aspectos essenciais do cuidado compartilhado e suas implicações. Por fim, e a partir dessa análise, discute a noção de cuidado em alimentação e nutrição (CAN), que emerge nas estratégias discursivas, considerando elementos como espacialidade, temporalidade, aspectos éticos, potencialidades e limitações.

Faz-se necessário enfatizar que será adotada a mesma terminologia usada no documento-referência, visto que à época de sua divulgação ainda não havia sido publicada a mais recente versão da Política Nacional de Atenção Básica ${ }^{18}$, que, entre outras medidas, alterou a nomenclatura de Núcleo de Apoio à Saúde da Família (NASF) para Núcleo Ampliado de Saúde da Família e Atenção Básica (Nasf-AB). 


\section{Contexto de produção e estratégias discursivas adotadas no documento-referência}

O documento em estudo, aqui denominado documento-referência, integra um conjunto de produções do Ministério da Saúde brasileiro voltadas à APS. Tal publicação sucedeu a implementação de programas e políticas públicas que impulsionaram pesquisas com ampla diversidade de objetos e desenhos metodológicos no campo da alimentação e nutrição ${ }^{1,2,19}$.

O texto foi elaborado por cinco nutricionistas, em parceria com uma extensa equipe de profissionais de saúde oriundos de diferentes áreas de formação, todos com experiência prática e/ ou pós-graduação nas áreas de saúde coletiva e saúde da família. Autores que transitam em espaços de ensino, serviço e gestão no âmbito da APS, e cujas perspectivas complementares acerca dos modos de atuar foram articuladas ao longo do texto.

Destinado a trabalhadores e gestores, apresenta como objetivo "compartilhar conhecimentos produzidos pelas vivências e reflexões sobre os modos de fazer o apoio matricial em alimentação e nutrição", por meio da "apresentação de ferramentas e conhecimentos que fomentem a reflexão sobre o processo de trabalho dos NASF junto às equipes de referência da Atenção Básica no tocante aos Cuidados em Alimentação e Nutrição"12 (p. 5).

Está organizado em três capítulos. O último e mais extenso, intitulado "Práticas de apoio matricial para a atenção nutricional”, apresenta cinco casos fictícios baseados em seus principais pilares: a experiência e o conhecimento científico. Tal posicionamento possivelmente está relacionado ao lugar de fala dos autores: trabalhadores da saúde que, de alguma forma, contribuíram para o processo histórico de construção, registro, sistematização e análise dos modos de atuação no apoio matricial.

O documento-referência se diferencia do conjunto de publicações oficiais ao se apoiar sobre elementos do pensamento complexo, atribuindo destaque às práticas de cuidado, notadamente presentes no último capítulo, que, por esse motivo, constituiu o cerne desta análise ${ }^{16,17}$.

Em consonância com Morin ${ }^{16}$, a complexidade será aqui compreendida como um tecido dinâmico de constituintes heterogêneas (ações, retroações, interações, acontecimentos) associadas de maneira inseparável. Tal entendimento se apoia, ainda, nos estudos praxiológicos de $\mathrm{Mol}^{17}$, que expõem práticas de cuidado como constitutivas da realidade complexa, ligada à coexistência entre complementaridade e antagonismo, ordem e desordem, saúde e doença, cujos limites não podem ser absolutamente demarcados.

Assim, o uso de narrativas para o compartilhamento de conhecimentos produzidos a partir das experiências foi identificado como principal estratégia discursiva. A linguagem simples, combinada a termos técnicos, alcança o leitor, contando-lhe histórias com as quais possivelmente tem alguma familiaridade, propondo-lhe outros olhares para os atores envolvidos e seus modos de atuar. Como parte dos esforços de acercamento da realidade, o CAN é contextualizado em diferentes enredos, cuja incompletude é apresentada como ponto fulcral para o entendimento da imprevisibilidade e das incertezas em sua relação com a dinâmica das vidas dos usuários.

Indagações sucedem as narrativas, remetendo trabalhadores da saúde à própria realidade, estimulando-os a pensar sobre os objetivos e estratégias que adotariam para lidar com as situações descritas e sobre as formas de atuação vigentes no seu município ou território. Além da ênfase no caráter singular das circunstâncias e do estímulo à reflexividade, há indicações de referências, ferramentas e estratégias para ampliação do conhecimento e qualificação da atenção nutricional.

A alimentação aparece envolta em múltiplos e inseparáveis aspectos (comensalidade, afeto, corporalidade, ordenações, racionalidades), sendo considerada um fenômeno social, circunstancial, situado e relacionado à diversidade e à situação de saúde dos territórios. A multiplicidade de atores nas histórias remete à diversidade de lógicas nos processos de interação.

Desse modo, o documento-referência apresenta outras apropriações e interpretações, cujas implicações serão discutidas na continuidade deste texto.

\section{Deslocamentos, desenlaces e tessituras: experiência e cinesia na produção do cuidado em alimentação e nutrição}

Da assunção da complexidade, deriva a compreensão do CAN como processo e a interpretação de suas demandas e dificuldades como "nós" a serem desatados ${ }^{12}$ (p. 27). Tal figura de linguagem faz alusão à ocorrência de enlaçamentos mais acirrados nos emaranhados que envolvem a alimentação ao longo da vida, dos quais podem dimanar efeitos indesejados. Além disso, as histórias relatam uma sequência de fatos com- 
plicadores, cujo lidar cotidiano ocorre em meio a conflitos, divergências e adversidades. Demonstra que, no desenvolvimento da atenção nutricional, não há um único problema a resolver. Não há um único nó a desatar, e muitos deles são criados justamente nas tentativas de desenlace.

Conforme essa interpretação, que se estende às tramas dos casos fictícios, as práticas de CAN têm início com os esforços para identificar e compreender as interseções e a definição de quais aspectos serão manejados. Continua com sucessivas tentativas, por meio de uma série de ações, que podem gerar a resolubilidade (completa ou parcial) e problemas não previstos. A ideia de ordenamento está presente, mas é relativizada pelas incertezas, que perpassam os itinerários, representados por outra metáfora: o "caminho de erros e acertos"12 (p. 35).

Assim, é possível depreender que, ao admitir a desordem inerente à realidade e manejá-la cotidianamente em interação com outros atores, $\mathrm{o}$ desenlace dos fios implica deslocar e deslocar-se, dando origem a novas (e nem sempre previstas) tessituras. Nessa categoria, serão analisados os já citados recursos metafóricos adotados no documento-referência, considerando sua contribuição para a emergência de uma noção de CAN.

Nas reflexões a respeito do "caminho de erros e acertos" serão explorados dois deslocamentos. $\mathrm{O}$ deslocamento da biomedicina de sua posição central na sustentação e condução das práticas de cuidado e o deslocamento do profissional de saúde enquanto sujeito da experiência, que vivencia a coprodução de outros modos de cuidar. Embora sejam apresentados em sequência para efeito de discussão, a "repercussividade" entre eles viabiliza o trânsito entre generalidade e singularidade, entre redução e complexidade na produção do CAN. Em seguida, nas ponderações sobre os "nós" a serem desatados, inspiradas pela relação entre ordem, desordem e organização descrita por Morin ${ }^{16}$, serão abordados os desenlaces como processos fecundos para a elaboração de tessituras mais complexas na produção do cuidado e no desenvolvimento de habilidades pelos cuidadores.

Dando continuidade à efetivação da clínica ampliada na APS, múltiplos atores foram inseridos, propondo e reconfigurando processos de trabalho e modos de interação. Pela ampliação do sujeito da atenção para indivíduo-família-comunidade, a tradicional díade profissional-paciente tornou-se uma miríade. Pela conjunção entre equipes de referência e de apoio matricial, às primeiras coube a responsabilidade pela realização e coordenação da assistência aos casos, e às segundas a retaguarda assistencial e o suporte técnico-pedagógico. Pela proximidade com os usuários em seu território, a ambas coube a tarefa de construir vínculos e articular diferentes núcleos de saber. Assim, a interdisciplinaridade no trabalho em saúde buscou a ampliação e o aperfeiçoamento do cuidado ${ }^{7,14}$.

Sobre a atenção nutricional realizada por meio desse arranjo organizacional, o documento-referência expõe a finalidade de "aumentar a capacidade de análise e resolução de problemas relacionados a alimentação e nutrição, tanto no âmbito individual quanto coletivo"12 (p.13), e procura ilustrá-la em diferentes situações.

O caso fictício "Atenção nutricional como parte do Projeto Terapêutico Singular (PTS)" relata o processo de produção do cuidado a uma mulher idosa, portadora de diabetes mellitus com complicações. Na história, a "equipe azul da UBS Castelinho" e a equipe NASF analisam os dados epidemiológicos do território e identificam o caso da "senhora Florentina", cuja "complexidade típica" justificaria a elaboração do PTS $^{12}$ (p. 19). A usuária é convidada a comparecer à UBS em companhia dos familiares para falar "sobre a sua história, a composição de sua família" e a "relação com seu autocuidado" 12 (p. 20). Tal aproximação se estende ao espaço doméstico e possibilita a elaboração de estratégias terapêuticas mais específicas. Em conformidade com princípios e etapas propostos no PTS, diagnóstico, metas e responsabilidades são então definidos. A narrativa é finalizada sem que os resultados sejam revelados.

A intenção de avançar "para além do critério diagnóstico biomédico"12 (p. 19) é ratificada na introdução da referida narrativa. A riqueza de detalhes e a nomeação dos atores distinguem e contextualizam o perene adoecimento no curso sinuoso de uma vida e inserem a produção do CAN no tempo de forma longitudinal, situando -o em diferentes espaços.

A equipe de referência revisa o "plano terapêutico (hábitos alimentares, atividade física, tratamento medicamentoso)" repetidas vezes sem obter êxito ${ }^{12}$ (p. 20). Com o apoio da equipe NASF, a estratégia é modificada e ampliada, com base em um processo dialógico mediado pelo PTS. Os membros das equipes, a usuária e seus familiares são apresentados como copartícipes e atuam em tentativas, conforme suas habilidades. Ao longo da história, não há menção a um ator principal, mas à potência da associação entre eles para a produção do CAN.

Em visita domiciliar, a enfermeira identifica a dificuldade da usuária em aspirar a dose ade- 
quada de insulina na seringa devido à perda da acuidade visual. Além do encaminhamento para tratamento oftalmológico, "Maria”, neta da "sra. Florentina”, é chamada para atuar em substituição à filha "Laura", impossibilitada de prestar apoio no preparo das refeições e na administração de medicamentos devido aos horários de trabalho. Portanto, o acompanhamento longitudinal descrito na história parte da aproximação com o cotidiano para reestruturar as redes assistenciais pela inclusão ou reposicionamento de atores nos âmbitos institucional e doméstico.

Por meio dos casos, o documento-referência expõe atritos e conflitos entre profissionais, gestores, usuários e familiares. Aponta negociações, diálogos e a construção de pactos como caminhos que viabilizam resoluções, ainda que temporárias. Partindo da assunção de que o contexto é instável, pelo fato de abrigar múltiplas forças e tensões, denota, ainda que de modo implícito, a flexibilidade e a mobilidade entre os atores como sustentáculo das redes que se dedicam à produção do $\mathrm{CAN}^{17}$. E aponta instrumentos úteis no processo de cogestão e coprodução do CAN.

Enquanto dispositivo de integração e direcionamento das práticas de cuidado, o PTS busca a superação da racionalidade biomédica. Ao operar essencialmente com o conceito de singularidade dos sujeitos (individual ou coletivo), alarga a diagnose e conduz a elaboração de uma terapêutica também singular, ampliada e compartilhada ${ }^{3,20,21}$. Contudo, ao considerar a atenção nutricional, a operacionalização do PTS descrita no caso revela outra dimensão dos movimentos: o deslocamento das ideias de precisão, previsibilidade.

Ao longo da história, os resultados de exames e da avaliação antropométrica da sra. Florentina são listados. No entanto, não são apresentados ao lado de padrões de normalidade. Os dados obtidos no inquérito alimentar não são exatamente quantificados ou classificados em termos de fracionamento, valor nutricional ou qualidade dos alimentos consumidos. E ainda apresentam outras informações complementares sobre a alimentação: "Gosta de comer de vez em quando o almoço acompanhado de uma banana. Prepara essa refeição no capricho, para ela e o esposo. A única da casa que come verduras e legumes é a neta, e a Sra. Florentina separa com carinho a porção para ela. Diz que não consegue comer verdura, porque acha que não tem gosto de nada. Se tiver alguma visita à tarde, ela serve cafezinho com bolacha de água e sal com margarina ou bolo de fubá. Do contrário, só volta a comer à noite, às 18 horas, quando a filha retorna do tra- balho. O jantar da família geralmente é sopa de feijão com macarrão e carne, ou algo que tenha sobrado do almoço"12 (p. 21).

Assim, os autores fazem alusão a outros aspectos, como gosto, comensalidade, sociabilidade, arranjos cotidianos e ao cuidado mediado pela comida, mas reservam ao leitor a tarefa de interpretá-los.

Além disso, a dimensão da terapêutica não é apresentada sob a forma de prescrição dietética. Há referência à "mudança nos hábitos alimentares" como uma das metas a serem alcançadas “com orientação do nutricionista", por meio da "construção e pactuação de estratégias alimentares", junto a usuária e familiares, e o "monitoramento e avaliação das mesmas" pelos membros da $\operatorname{ESF}^{12}$ (p. 22). Em um desfecho que permanece aberto, não há garantias do sucesso das estratégias: "Após dois meses de implementação do PTS, a equipe reuniu-se para avaliar o plano"12 (p.23).

Em se tratando de uma publicação oficial, é importante destacar que nem todas as práticas são descritas e não há um modelo de conduta clínica exato, que poderia ser adotado em situações semelhantes. Ao se dirigir ao nutricionista na condição de leitor, estimulando-o a pensar sobre quais seriam os seus objetivos, estratégias alimentares propostas e contribuições na vertente técnico-pedagógica, o documento-referência aponta que outras formas de atuar são possíveis e legítimas ${ }^{17}$.

Nesse quesito, o contraste será adotado como um recurso para a melhor compreensão do deslocamento em discussão. Contudo, faz-se necessário enfatizar que não há noções em sua forma pura e as práticas de cuidado são híbridas, relacionais e circunstanciais ${ }^{17,22}$.

O pensamento positivista, a perspectiva reducionista e a racionalidade biomédica ainda são hegemônicos nos estudos no campo da alimentação e nutrição ${ }^{19,23}$. Embora não determine as práticas de produção científica e de cuidado, essa dimensão epistemológica as constitui, sustenta, atravessa e se faz presente ainda que como uma tendência ou inclinação.

Mensurações, cálculos e aferições convertem o corpo, a alimentação e a doença em medidas, índices, discrepâncias numéricas. Ao operar essa tradução identificada como um tipo específico de tecnologia biomédica ${ }^{24}$, diagnóstico e prescrição dietética ocorrem por meio da objetivação, apoiando-se sobre as certezas conferidas pela precisão dos cálculos.

Metrificados, os sujeitos são substituídos por padrões numéricos que, por sua vez, produzem 
a imagem de similaridade e homogeneidade dos corpos, da alimentação, dos modos de vida ${ }^{25,26}$. As generalizações criam uma aparente segurança ao promover o entendimento do cuidado relacionado a alimentação e nutrição como intervenção acurada, plenamente gerenciável pelo pensamento matemático, portanto de resultados previsíveis. No interior dessa compreensão, o cuidado se assemelha a um experimento reprodutível, desde que excluídas as variáveis que podem causar confusão $0^{17,27,28}$. Suprimindo ou afastando relações (arranjos familiares, gênero, gostos, identidade, cultura, religiosidade, entre outras), números são usados de modo preponderante para corrigir ou controlar outros números.

Dessa forma, a conduta estaria baseada na aplicação do conhecimento científico e o êxito técnico dependeria principalmente da obediência às regras, do rigoroso seguimento da dieta prescrita, do comer com exatidão. A atuação dos sujeitos envolvidos seria esmaecida pela execução mimética dos papeis de profissional ou usuário. Em prol da restituição de uma ordem idealizada, o cuidado seria um modo de fazer cessar processos fisiopatológicos, controlar dimensões corporais, conter impulsos e prazeres por meio da alimentação, alcançar a normalidade.

Como consequências dessa noção ainda vigente, pesquisadores mais críticos do campo apontam a medicalização do corpo e do comer $^{29}$, o desenvolvimento de uma racionalidade nutricional ${ }^{30}$, o uso do discurso da alimentação saudável como estratégia de biopoder ${ }^{31}$, a adoção de estratégias de incentivo ao autocuidado com foco no autocontrole $^{32}$, a idealização da magreza como atributo de saúde ${ }^{25}$ e a preponderância das relações de mercado orientadas ao consumo cada vez maior de artefatos e dispositivos para o autocuidado ${ }^{17}$.

Esse processo fragmentário, que mormente considera a singularidade biológica, é de alguma forma desconstruído pelo contato com o contexto e a dinâmica da vida dos sujeitos na APS $^{26,33}$. O convívio com os grupos familiares e a comunidade aproxima os profissionais do ambiente, das vidas em relação e do comer cotidiano, plenos de instabilidade, variabilidade e, portanto, imprevisibilidade.

Generalidade e singularidade coexistem no documento-referência. Na construção dos casos fictícios, a análise dos dados populacionais é reiterada como ferramenta de gestão clínica. Por outro lado, as narrativas apontam para realidades únicas, contextuais, em constante fluxo.

Ainda que a tecnologia biomédica de objetivação esteja presente, ela não é central para o diagnóstico e a terapêutica. Tecnologias relacionais também estão em operação e há outros valores em $\mathrm{jogo}^{17}$. As narrativas demonstram que as incertezas invadem o trabalho na APS e não é possível erradicá-las. A atenção longitudinal precisa lidar com o curso do tempo e com a inconstância que lhe é inerente. Nas histórias, em meio a conflitos e tensões, e não apenas por meio dos números, pessoas cuidam de pessoas.

O repertório do conhecimento técnico é ampliado pelo diálogo com as ciências sociais e humanas, cujo referencial é indicado pelos autores somente após a apresentação das questões que buscam estimular a reflexividade pelo leitor. Desse modo, a ciência é deslocada do estatuto de verdade única, ante a autonomia e a agência daqueles que dela fazem uso. Feita em tentativas, a produção do CAN apresentada no documento -referência é condicional e assume o sentido, não de experimento, mas de experimentação ${ }^{28}$. Seus resultados não são previsíveis, nem sempre são exitosos, não mais estão no campo das certezas.

O reconhecimento e o acolhimento das incertezas têm sido apontados como um posicionamento imprescindível ao desenvolvimento de habilidades e proficiência dos profissionais de saúde. Nesse sentido, a capacidade de relacionar a singularidade e a complexidade dos casos com a generalidade das evidências científicas no trabalho cotidiano é ressaltada como fundamental para o avanço da diagnose e da terapêutica na APS $^{20,26,33}$.

Em se tratando da compreensão do CAN, pelo acolhimento das incertezas, a atuação é redirecionada para apoiar-se mais em princípios do que em normas e regras de conduta. No crescente espaço concedido às interações, a biomedicina é deslocada de sua posição central. Desse modo, pode haver mais humanização e integralidade do que simplificação e opacidade, que por sua vez propiciam o deslocamento do profissional de saúde enquanto sujeito da experiência.

Outros excertos da publicação remetem à compreensão de que o rearranjo organizacional e o trabalho por meio do apoio matricial implicam deslocamentos do profissional. Demove-o não apenas do espaço privado do consultório, mas de pensamentos hegemônicos acerca de fenômenos complexos como a alimentação e a obesidade, das modalidades de abordagem disciplinadoras e prescritivas e de lógicas como a que restritamente associava a prática clínica na APS ao atendimento ambulatorial de indivíduos doentes. Reaproxima -o das práticas culinárias como forma de promover reconfigurações das relações dos sujeitos 
com os seus corpos, com a comida e com o ato de comer.

Como personagens das histórias, os profissionais parecem representar as ciências na produção de conhecimentos excessivamente teóricos, normativos, disciplinadores, pouco aplicáveis às vidas reais e que, por esse motivo, precisam ser revistos e transformados. Afetados diretamente pela experiência, veem-se desafiados a criar outros modos de agir. O desenvolvimento de conhecimentos técnicos e habilidades para o manejo compartilhado dos fios, a partir de uma visão ampliada dos entrelaçamentos, forma (em serviço) um outro profissional, que tece a si mesmo na relação com outrem.

Sob essa ótica, a experiência provocada pelos desenlaces pode ser vista como fonte fecunda do saber construído a partir da experiência. Um saber pleno de sentido, feito na relação entre vida humana, alimentação e conhecimento. Um saber que emerge no sujeito que se expõe, inventando trilhas, arriscando direções, exercitando o caminhar junto, negociando caminhos a seguir. Pelo exercício da autonomia e criatividade nos encontros com os demais atores, profissionais de saúde criam modos de atuar por meio das tecnologias biomédicas de objetivação, sem deixar-se subordinar, por vezes subvertendo-as, desenvolvendo em si a sabedoria prática ${ }^{28,34,35}$.

Além das tessituras do cuidado e das tessituras de si, é importante destacar a tessitura de novos referenciais técnicos, que diversificam o cenário de publicações normativas e podem provocar mudanças no processo de formação. Ambas evidenciam que a complexidade dos emaranhados não deve ser afastada, reduzida, suprimida, pois pode ser fecunda, formadora, transformadora.

\section{Uma noção de cuidado em alimentação e nutrição emerge nas tessituras}

A partir dos elementos identificados no documento-referência, é possível afirmar que emerge das estratégias discursivas uma noção baseada na compreensão do CAN como manejo compartilhado. Manejo no sentido de tatear, de perceber e criar por meio das experiências provocadas por esse contato, maneiras de lidar com as intrincadas ligações entre alimentação, nutrição e saúde no contexto da vida. São emaranhados que solicitam diferentes perspectivas e habilidades para inventar e realizar os movimentos (dos fios e de si mesmo) nessa ou naquela direção. Portanto, a sensibilidade para perceber e lidar com as demandas é fundamental e requer colaboração e complementaridade entre aqueles (gestores e equipes de referência e de apoio matricial) que se responsabilizam por desatar os nós. A restituição da ordem é também um objetivo presente nessa compreensão, mas se trata de uma ordem possível e sempre provisória.

Portanto, essa noção de CAN se aproxima daquilo que $\mathrm{Mol}^{17}$ descreveu como um processo aberto, no qual várias mãos trabalham juntas, continuamente, para atender às especificidades dos problemas, dos indivíduos e das circunstâncias.

Ao apresentar práticas situadas que se estendem pelo território, tal compreensão demonstra uma visão ampliada acerca da espacialidade do CAN, indicando a influência de ambiências e materialidades sobre o processo, que parece estar sempre em curso e se desdobrar em uma temporalidade particular ${ }^{36-38}$.

Ao reconhecer e visibilizar a diversidade de atores e de modos de atuar, reforça a natureza estruturante da corresponsabilidade, admitindo a coexistência entre autonomia e heteronomia na produção do cuidado. Outro aspecto ético relevante é a proximidade com a realidade pela exposição de falhas e equívocos. Desse modo, as repetidas (e nem sempre exitosas) tentativas de desatar os nós e a relativização da resolubilidade parecem constituir o ethos desse modo de conceber o $\mathrm{CAN}^{38,39}$.

Nesse sentido, o compartilhamento das práticas de cuidado expõe a potência dos engajamentos e também implica ressonâncias, interdependências e negociações constantes. Diferentes saberes e habilidades estão em jogo no uso criativo de tecnologias biomédicas e relacionais, sempre a partir da realidade dinâmica dos emaranhados. A artesania e singularidade do CAN apontam para a adaptabilidade como princípio orientador das experimentações e ajustamentos ao longo do processo de lidar com a complexidade da alimentação, com a erraticidade do adoecimento, as incertezas, ambivalências e impossibilidade de pleno controle dos corpos e do comer $^{17,36,38}$.

O documento-referência não provoca rupturas com as construções dominantes. Por outro lado, em vez de isoladas ou ignoradas em favor de um direcionamento estrito das condutas terapêuticas, ambiguidades, contradições e complicações relacionadas à alimentação no cotidiano são admitidas como parte do processo, que se mantém aberto. Embora faça críticas contundentes à compreensão hegemônica, esta não é completamente repelida, e sim relida, reinterpretada. 
Conduzidas por outras lógicas, as tentativas de desprendimento dos fios diferem de sua ordinária cisão.

Para Morin ${ }^{16}$, a desordem, a organização e a ordem são fenômenos contínuos e simultâneos no universo. A organização não expulsa a desordem. Esta se dá pela desintegração e constituição da ordem tornada mais complexa. Mol e $\mathrm{Law}^{27}$ acrescentam que a ordem é multiplicada. Transformada em várias ordens, que podem estar em tensão.

Em conformidade com tais considerações, é possível afirmar que a assunção da complexidade e a intensidade das experiências de cuidado provocadas pelo apoio matricial evidenciaram a insuficiência da noção hegemônica e propiciaram o surgimento de outras compreensões de CAN. Uma delas está expressa no documento-referência e, ainda que reproduza conceitos e definições, traz mudanças significativas que pluralizam o conjunto de publicações normativas. Abre espaço para outros avanços.

\section{Considerações finais}

A publicização do documento oficial analisado neste texto foi antecedida por avanços e conquistas no campo da saúde coletiva no Brasil, que no bojo da construção de perspectivas ampliadas do cuidado colocou em evidência o papel determinante da alimentação para a saúde da população. Contudo, a despeito da crescente produção de conhecimentos e publicações técnicas para nortear ações no âmbito da APS, ele surgiu em um contexto no qual a dimensão do cuidado em saúde referente a alimentação e nutrição foi mantida na opacidade dos múltiplos termos e da ausência de discussões conceituais. Esse cenário lacunar, somado às reconfigurações propostas pelas mudanças no modelo de atenção, possivelmente mobilizaram os autores a compartilhar vivências que pudessem instrumentalizar o desenvolvimento do CAN por profissionais e gestores inseridos no apoio matricial, implantado há pouco mais de uma década.

A adoção de estratégias discursivas, entre as quais destaca-se o uso de narrativas, evidencia a relevância atribuída à experiência no processo de elaboração. $\mathrm{O}$ documento-referência emerge da experiência e a ela se volta trazendo contribuições. As histórias situam a produção do cuidado em diferentes espaços, contextualizando-o no curso do tempo, na vida dos usuários, na rotina dos trabalhadores. Os relatos expõem conflitos, adversidades, potencialidades e outras dimensões da realidade habitualmente ignoradas em publicações dessa natureza. Os autores evitam emitir juízos de valor ou o fazem com cautela, reiterando o respeito à singularidade das circunstâncias e das perspectivas dos leitores, cuja reflexividade estimulam com indagações pertinentes.

No processo analítico, foram identificados recursos metafóricos que se referem aos deslocamentos epistemológicos e à cinesia provocada pela experiência de profissionais, ante à insuficiência da atuação insulada e reducionista. A repercussividade entre tais deslocamentos possibilita, por sua vez, o trânsito entre generalidade e singularidade, necessário às tentativas de organização da realidade na atenção primária.

Transpondo as publicações oficiais que referencia, o documento-referência apresenta elementos do pensamento complexo como constitutivos da noção de CAN, sendo esta manifestada como um manejo compartilhado de práticas de cuidado dialogadas e partilhadas entre profissionais, gestores, usuários, familiares e comunidade por meio do apoio matricial. Trata-se de um processo contínuo, aberto, dinâmico e plural no lidar cotidiano com situações complexas, partindo de uma compreensão ampliada da relação entre saúde e alimentação e tendo como horizonte a melhora do estado de saúde e da qualidade de vida. Não há rupturas, mas releituras das construções anteriores, pois ao divisar e admitir outras dimensões da realidade, avança na direção da integralidade.

É importante destacar que, por se tratar de uma produção textual, as análises se restringem àquilo que foi expresso no texto. Contudo, ao modificar o cenário de produções normativas e colocar em evidência a pluralidade de modos de compreender e atuar, o documento-referência suscita investigações que se voltem às práticas de CAN. Como ocorrem as interações entre os atores? De que modo lidam com situações de vulnerabilidade social quando esta está no cerne dos emaranhados que envolvem a alimentação? Uma vez que o deslocamento da biomedicina é apontado, em que outras racionalidades e bases epistemológicas se apoiam os profissionais para a produção do CAN? Como discutir conceitualmente o CAN se considerarmos a sua diversidade e dinamicidade? De que forma são consideradas as relações de gênero e posição social?

O documento-referência desafia os profissionais e pesquisadores a desenvolverem um novo campo de investigações, que pode contribuir para a qualificação das práticas assistenciais. 


\section{Colaboradores}

LM Magalhães e LAS Santos participaram da concepção do estudo, da análise e interpretação dos resultados e da redação do artigo. DC LeãoSantos e IR Gomes colaboraram com a interpretação dos dados e a revisão crítica do texto final.

\section{Agradecimentos}

Ao Conselho Nacional de Desenvolvimento Científico e Tecnológico (CNPq) e à Fundação de Amparo à Pesquisa do Estado da Bahia pelo apoio financeiro.

\section{Referências}

1. Recine E, Vasconcellos AB. Políticas nacionais e o campo da alimentação e nutrição em saúde coletiva: cenário atual. Cien Saude Colet 2011; 16(1):73-79.

2. Jaime PC, Silva ACF, Lima AMC, Bortolini GA. Ações de alimentação e nutrição na atenção básica: a experiência de organização no Governo Brasileiro. Rev Nutr 2011; 24(6):809-824.

3. Campos GW, Bedrikow R. História da clínica e atenção básica: o desafio da ampliação. São Paulo: Hucitech; 2014.

4. Jaime PC, Delmuè DCC, Campello T, Silva DO, Santos LMP. Um olhar sobre a agenda de alimentação e nutrição nos trinta anos do Sistema Único de Saúde. Cien Saude Colet 2018; 23(6):1829-1836.

5. Cecilio LCO, Reis AAC. Apontamentos sobre os desafios (ainda) atuais da atenção básica à saúde. Cad Saude Publica 2018; 34(8):e00056917.

6. Brasil. Ministério da Saúde (MS). Secretaria de Atenção à Saúde. Departamento de Atenção Básica. Cadernos de Atenção Básica - Diretrizes do NASF: Núcleo de Apoio Saúde da Família, nº 27. Brasília: MS; 2010.

7. Brasil. Ministério da Saúde (MS). Secretaria de Atenção à Saúde. Departamento de Atenção Básica. Cadernos de Atenção Básica - Núcleo de Apoio a Saúde da Família: ferramentas para a gestão e para o trabalho cotidiano, $\mathrm{n}^{\circ} 39$. Brasília: MS; 2014.

8. Brasil. Ministério da Saúde (MS). Matriz de ações de alimentação e nutrição na atenção básica de saúde. Brasília: MS; 2009.

9. Brasil. Ministério da Saúde (MS). Secretaria de Atenção à Saúde. Departamento de Atenção Básica. Política Nacional de Alimentação e Nutrição. Brasília: MS; 2012

10. Brasil. Ministério da Saúde (MS). Guia alimentar para a população brasileira. Brasília: MS; 2014.

11. Brasil. Ministério da Saúde (MS). Instrutivo: metodologia de trabalho em grupos para ações de alimentação e nutrição na Atenção Básica. Brasília: MS; 2016.

12. Brasil. Ministério da Saúde (MS). Contribuições dos Núcleos de Apoio à Saúde da Família para a Atenção Nutricional. Brasília: MS; 2017.

13. Brasil. Ministério da Saúde (MS). Secretaria de Atenção à Saúde. Departamento de Atenção Básica. Cadernos de Atenção Básica - Estratégias para o cuidado da pessoa com doença crônica: obesidade, $n^{\circ} 38$. Brasília: MS; 2014.

14. Orlandi EP. Análise de discurso. Campinas: Pontes, 2005.

15. Poupart J, Deslauriers JP, Groulx LH, Laperriere A, Mayer R, Pires AP. A pesquisa qualitativa: enfoques epistemológicos e metodológicos. Petrópolis: Vozes; 2008.

16. Morin E. Introdução ao pensamento complexo. Porto Alegre: Sulina; 2015.

17. Mol A. The logic of care: health and the problem of patient choice. New York: Routledge; 2008.

18. Brasil. Portaria ${ }^{\circ} 2.436$, de 21 de setembro de 2017. Aprova a Política Nacional de Atenção Básica, estabelecendo a revisão de diretrizes para a organização da atenção básica. Diário Oficial da União 2017; 22 set.

19. Canella DS, Silva ACF, Jaime PC. Produção científica sobre nutrição no âmbito da atenção primária à saúde no Brasil: uma revisão de literatura. Cien Saude Colet 2013; 18(2):297-307. 
20. Cunha GT, Campos GWS. Apoio matricial e atenção primária em saúde. Saúde Soc 2011; 20(4):961-970.

21. Oliveira GN. O projeto terapêutico singular. In: Campos GWS, Guerrero AVP, organizadores. Manual de práticas de atenção básica saúde ampliada e compartilhada. São Paulo: Hucitec; 2010. p. 283-297.

22. Cohn S. From health behaviours to health practices: an introduction. Sociol Health Illn 2014; 36(2):157162.

23. Freitas MCS, Minayo, MCS, Fontes, GAV. Sobre o campo da alimentação e nutrição na perspectiva das teorias compreensivas. Cien Saude Colet 2011; 16(1):31-38.

24. Lock M, Nguyen VK. An anthropology of biomedicine. Malden: Wiley-Blackwell; 2010.

25. Yates-Doerr E. The weight of obesity: hunger and global health in postwar Guatemala. Berkeley: Univ of California Press; 2015.

26. Malterud K, Guassora AD, Reventlow S, Jutel A. Embracing uncertainty to advance diagnosis in general practice. Br J Gen Pract 2017; 67(659):244-245.

27. Law J, Mol A. Complexities: an introduction. In: Law J, Mol A, organizadores. Complexities: social studies of knowledge practices. Durham: Duke University Press; 2002. p. 1-22.

28. Bondía JL. Notas sobre a experiência e o saber da experiência. Rev Bras Educ 2002; (19):20-28.

29. Gracia-Arnaiz M. Comer bien, comer mal: la medicalización del comportamiento alimentario. Salud Publica Mex 2007; 49(3):236-242.

30. Viana MR, Neves AS, Camargo Junior KR, Prado SD, Mendonça ALO. A racionalidade nutricional e sua influência na medicalização da comida no Brasil. Cien Saude Colet 2017; 22(2):447-456.

31. Kraemer FB, Prado SD, Ferreira FR, Carvalho MCVSD. O discurso sobre a alimentação saudável como estratégia de biopoder. Physis 2014; 24(4):1337-1359.
32. Castiel LD, Ferreira MS, Moraes DR. Os riscos e a promoção do autocontrole na saúde alimentar: moralismo, biopolítica e crítica parresiasta. Cien Saude Colet 2014; 19(5):1523-1532.

33. Simpkin AL, Schwartzstein RM. Tolerating uncertainty - the next medical revolution? N Engl J Med 2016; 375(18):1713-1715.

34. Ayres JRCM. Cuidado: tecnologia ou sabedoria prática? Interface 2000; 4(6):117-120.

35. Franco TB. Trabalho criativo e cuidado em saúde: um debate a partir dos conceitos de servidão e liberdade. Saúde Soc 2015; 24(1):102-114.

36. Abbots EJ, Lavis A, Attala L. Careful eating: bodies, food and care. Farnham: Ashgate; 2015.

37. Buse C, Martin D, Nettleton S. Conceptualising 'materialities of care': making visible mundane material culture in health and social care contexts. Sociol Health Illn 2018; 40(2):243-255.

38. Mol A, Moser I, Pols I, organizadores. Care in Practice. On tinkering in clinics, homes and farms. Germany: Transcript Verlag; 2010.

39. Devish I. Co-responsibility: a new horizon for today's health care? Health Care Anal 2012; 20(2):139-151.

Artigo apresentado em 03/04/2019

Aprovado em 25/11/2019

Versão final apresentada em 27/11/2019

Editores-chefes: Romeu Gomes, Antônio Augusto Moura da Silva 